\section{Distribution and malignancy risk of six categories of the pathology reporting system for thyroid core-needle biopsy in 1,216 consecutive thyroid nodules}

Hye Min Son ${ }^{1,2}$, Ji-hoon Kim', Soo Chin Kim³ ${ }^{3}$ Roh-Eul Yoo', Jeong Mo Bae ${ }^{4}$, Hyobin Seo ${ }^{3,5}$, Dong Gyu $\mathrm{Na}^{5,6}$

'Department of Radiology, Seoul National University Hospital, Seoul; ${ }^{2}$ Department of Radiology, Yeungnam University College of Medicine, Daegu; ${ }^{3}$ Department of Radiology, Seoul National University Hospital Healthcare System Gangnam Center, Seoul; ${ }^{4}$ Department of Pathology, Seoul National University Hospital, Seoul; ${ }^{5}$ Department of Radiology, Human Medical Imaging and Intervention Center, Seoul; ${ }^{6}$ Department of Radiology, GangNeung Asan Hospital, Gangneung, Korea

Purpose: The purpose of this study was to present the distribution of lesions among the six categories of the pathology reporting system for thyroid core-needle biopsy (CNB), along with the range of malignancy risk of each category based on different diagnostic criteria for benignity in a clinical cohort.

Methods: For 1,216 consecutive nodules $(\geq 1 \mathrm{~cm})$ of 1,125 patients who underwent CNB at two hospitals, the diagnostic results based on the six categories of thyroid CNB were analyzed. Patients were divided into three groups according to prior fine-needle aspiration (FNA) status: second-line CNB for nodules where prior FNA yielded nondiagnostic or unsatisfactory results $(n=57)$, second-line CNB for nodules with prior FNA results of atypia/follicular lesion of undetermined significance (AUS/FLUS) ( $n=303)$, and first-line CNB ( $n=856)$.

Results: The proportion of nodules in each CNB category and the range of the malignancy rate for each category was as follows, in order from category I to VI: $1.8 \%, 23.1 \%-75.0 \% ; 57.9 \%$, $0.7 \%-16.7 \% ; 16.0 \%, 13.2 \%-46.7 \% ; 8.8 \%, 53.8 \%-56.8 \% ; 2.0 \%, 100 \%$; and $13.5 \%, 100 \%$. First-line CNB was associated with a higher rate of conclusive diagnoses (category II, IV, or VI) (725 of $856,84.7 \%$ ) than second-line CNB with prior nondiagnostic or AUS/FLUS FNA results (241 of 360, 66.9\%; $\mathrm{P}<0.001$ ).

Conclusion: The overall distribution of nodules across the six categories of thyroid CNB and the ranges of malignancy risk for those categories were presented in a clinical cohort. Firstline CNB tended to produce a higher rate of conclusive results than second-line CNB with prior inconclusive FNA results.

Keywords: Thyroid; Core needle biopsy; Malignancy risk; Incidence; Pathology report system

e-ultrasonography.org

Ultrasonography 39(2), April 2020

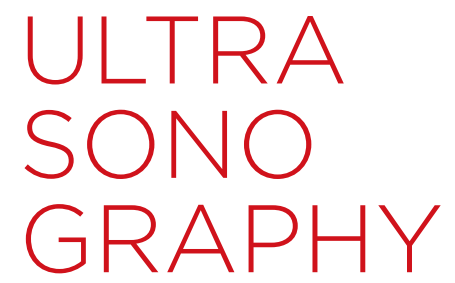

ORIGINAL ARTICLE

https://doi.org/10.14366/usg. 19056 pISSN: 2288-5919 - eISSN: 2288-5943 Ultrasonography 2020;39:159-165

Received: October 10, 2019

Revised: January 13, 2020

Accepted: January 16, 2020

Correspondence to:

Ji-hoon Kim, MD, Department of Radiology, Seoul National University Hospital, 101 Daehak-ro, Jongno-gu, Seoul 03080, Korea

Tel. +82-2-2072-3280

Fax. +82-2-747-7418

E-mail: jihnkim@gmail.com

This is an Open Access article distributed under the terms of the Creative Commons Attribution NonCommercial License (http://creativecommons.org/ licenses/by-nc/4.0/) which permits unrestricted noncommercial use, distribution, and reproduction in any medium, provided the original work is properly cited.

Copyright (C) 2020 Korean Society of Ultrasound in Medicine (KSUM)

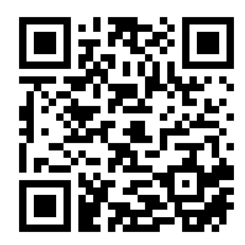

How to cite this article:

Son HM, Kim JH, Kim SC, Yoo RE, Bae JM, Seo $\mathrm{H}$, et al. Distribution and malignancy risk of six categories of the pathology reporting system for thyroid core-needle biopsy in 1,216 consecutive thyroid nodules. Ultrasonography. 2020 Apr;39(2):159-165. 


\section{Introduction}

Fine-needle aspiration (FNA) is the current diagnostic standard for thyroid nodules. However, due to its substantial rate of nondiagnostic and indeterminate results, various methods to enhance its diagnostic yield have been suggested [1-7]. Core-needle biopsy (CNB) has emerged as a diagnostic tool for thyroid nodules based on recent advances in core biopsy devices (spring-activated single- or double-action needles) and the widespread use of highresolution ultrasonography (US) $[8,9]$. CNB has been reported to be an effective and safe diagnostic tool, as it allows clinicians to obtain a core tissue sample with potential information on architectural histological structures, thus enabling immunochemical staining [1013]. Based on these advantages, many global guidelines have begun to recommend CNB as a diagnostic tool for thyroid nodules [14-17]. However, the preoperative diagnosis of thyroid cancer has traditionally been based on cellular nuclear features and the reporting system associated with cytologic specimens obtained via thyroid FNA. This system was standardized based on The Bethesda System for Reporting Thyroid Cytopathology (TBSRTC) [18]; however, there is currently no consensus regarding diagnostic criteria for reporting the pathologic results of thyroid CNB.

In this regard, to create pathologic diagnostic criteria for CNB, the Korean Endocrine Pathology Thyroid Core Needle Biopsy Study Group first proposed a 6 -tiered pathology reporting system for CNB of thyroid nodules in 2015 , based on a framework similar to the 2017 TBSRTC $[18,19]$.

Therefore, it is necessary to establish the malignancy risk and management protocol based on this 6-tiered system for CNB. Several studies have recently reported pathologic results based on this system $[20,21]$. However, their results included nodules smaller than $1 \mathrm{~cm}$, which are not indicated for FNA or CNB in the current guidelines $[17,22]$. In addition, those studies reported malignancy risks based on different reference standards for diagnosing benignity, even though the malignancy risk is known to differ according to the diagnostic reference standard $[20,21]$.

As such, the purpose of this study was to present the distribution of each category of the 6-tiered pathology reporting system of CNB for thyroid nodules $(\geq 1 \mathrm{~cm})$ in a clinical cohort, along with the malignancy risk of each category according to different diagnostic criteria for benignity.

\section{Materials and Methods}

\section{Study Population}

This study was approved by the institutional review board of our institution, and the requirement for informed consent was waived.
Between January 2010 and December 2014, 1,216 thyroid nodules $(\geq 1 \mathrm{~cm})$ tested using CNB at two medical centers were enrolled. The study population overlapped with that of two previous studies $[23,24]$. However, the topics of those studies were different from the present study, as one compared CNB with repeat FNA in the management of subcategories of thyroid nodules with atypia (or follicular lesion) of undetermined significance (AUS/FLUS) [23], while the other compared CNB and FNA as first-line diagnostic tools for thyroid nodules [24].

In the present study, the nodules were categorized into three groups according to the patients' previous FNA history: (1) secondline CNB for nodules with nondiagnostic FNA results $(4.7 \%, n=57)$,

(2) second-line CNB for nodules with AUS/FLUS results on FNA $(24.9 \%, n=303)$, or (3) first-line CNB (nodules without previous FNA; $70.4 \%, n=856$ ).

The indications for first-line CNB at our hospitals were as follows [15]: (1) nodules with any suspicious US feature [17]; (2) nodules with US results suggesting follicular neoplasm, such as solid nodules with well-defined smooth margins; (3) nodules with US findings indicative of inconclusive FNA results, such as heavily calcified, predominantly cystic, or fibrotic nodules; and (4) nodules for which CNB was requested by the referring clinician.

\section{US-Guided CNB Procedures and Pathologic Analysis}

Under the guidance of a high-resolution US apparatus (AplioXG, Toshiba, Otawarashi, Japan; IU22, Philips Medical Systems, Bothell, WA, USA) equipped with a 10- to $12-\mathrm{MHz}$ linear transducer, one of two radiologists (D.G.N and H.S., 15 and 7 years of experience in thyroid imaging and interventions, respectively) performed CNB using a disposable 18-gauge, single- or double-action springactivated needle (approximately 1- or 2-cm excursion; TSK Acecut or Stericut, Create Medic, Yokohama, Japan) as described in the literature [15], with one or two needle passes in most cases. Immediately after $\mathrm{CNB}$, the biopsy site was compressed by the operator; the patient was then observed for 20-30 minutes while performing manual self-compression of the biopsy site. There were no major complications, such as serious hemorrhage, and no patient required hospital admission or interventional management. The pathologic diagnoses of CNB were based on the 6-tiered reporting system proposed by the Korean Endocrine Pathology Thyroid Core Needle Biopsy Study Group [19]. From 1 to 6, the categories are nondiagnostic or unsatisfactory, benign lesion, indeterminate lesion, follicular neoplasm or suspicious for follicular neoplasm, suspicious for malignancy, and malignant. Category III (indeterminate lesion) is divided into three subcategories: indeterminate follicular lesion with nuclear atypia (IIIA), indeterminate follicular lesion with architectural atypia (IIIB), and other indeterminate lesion (IIIC). 


\section{Data Analysis and Statistics}

Based on the CNB results, the cancer classification, distribution of the pathologic results, and malignancy risk of each pathologic category was assessed according to the patients' previous FNA history. The final diagnosis of malignancy was made based on histopathologic readings from surgical resections or FNA and/ or CNB diagnosis of malignancy (category VI). The final diagnosis of a benign nodule was made when any of the following criteria was fulfilled: criterion I, surgical diagnosis or at least one benign diagnosis based on CNB or FNA (category II), if the lesion was not classified as category IV, V, or VI on previous or repeat FNA or CNB, if performed; criterion II, surgical diagnosis or at least two benign diagnoses on FNA and/or CNB; or criterion III, surgical diagnosis only.

The Fisher exact test was used to compare the distribution and malignancy risks of all categories in the entire population and among the subgroups. A 2-tailed P-value of $<0.05$ was considered to indicate statistical significance. Statistical analyses were performed using MedCalc version 11.1.1.0 (MedCalc Software, Mariakerke, Belgium).

\section{Results}

\section{Demographic Data of Patients and Pathologic Characteristics of Thyroid Nodules}

We evaluated a total of 1,216 thyroid nodules from 1,125 consecutive patients (male:female, 282:843; mean age, 49 years; age range, 13 to 95 years) that ranged in size (maximal diameter) from 1.0 to $11.3 \mathrm{~cm}$ (mean \pm standard deviation [SD], $2.0 \pm 1.1 \mathrm{~cm}$ ). These included 221 malignant nodules (18.2\%; size range, 1.0 to $8.0 \mathrm{~cm}$; mean $\pm S D, 17.0 \pm 9.4 \mathrm{~cm}$ ) from 220 patients (male:female, 60:160; mean age, 44.9 years; age range, 13 to 70 years) and 816 benign nodules ( $72.5 \%$; size range, 1.0 to $7.3 \mathrm{~cm}$; mean $\pm S D$, 20.0 $\pm 10.7 \mathrm{~cm}$ ) from 778 patients (male:female, 179:599; mean age, 50 years; age range, 15 to 86 years). The remaining 179 nodules from 176 patients did not fulfill the final pathologic criterion of a benign or malignant diagnosis.

Table 1 presents the diagnostic references and the final pathological diagnoses of the benign and malignant thyroid nodules analyzed in this study. Conventional papillary thyroid carcinoma (PTC) was the most common malignancy in categories I (3 of 3, 100\%), III ( 6 of $14,42.9 \%), V(9$ of $14,64.3 \%)$, and VI (161 of $164,98.2 \%$ ), and most of the conventional PTC cases (165 of 182, 90.7\%) were diagnosed as category VI. Follicular variant papillary thyroid carcinoma (FVPTC) was the most common malignancy in category II (3 of 5,60.0\%), and the FVPTC cases were variably diagnosed as category II to VI, most commonly as category IV (9 of $20,45.0 \%$ ).
Follicular thyroid carcinoma (FTC) was the most common malignancy in category IV (10 of $21,47.6 \%)$, and all FTC cases were diagnosed as either category III or (more commonly) as category IV (10 of 14 , $71.4 \%)$.

\section{Incidence and Malignancy Risk of Each Category on CNB}

The distribution of the 1,216 thyroid nodules among the CNB pathologic categories is summarized in Table 2. Compared with second-line CNB with prior FNA nondiagnostic results or AUS/FLUS, first-line CNB was associated with a higher rate of classification as categories II and VI and a lower rate of classification as categories III and IV, although there was no significant difference in the rate of classification as category II when the comparison was confined to first-line CNB versus second-line CNB with prior FNA nondiagnostic results. In addition, first-line CNB produced a higher rate of conclusive results (category II, IV, or VI) (725 of 856 [84.7\%] vs. 250 of $360[69.4 \%] ; P<0.001)$ and a lower rate of inconclusive results (category III) (97 of 856 [11.3\%] vs. 98 of 360 [27.2\%]; $P<0.001$ ) than second-line CNB for prior FNA nondiagnostic or AUS/FLUS.

Table 1. Diagnostic references and final pathological diagnoses of benign and malignant thyroid nodules

\begin{tabular}{|c|c|}
\hline & №. (\%) \\
\hline \multicolumn{2}{|l|}{ Diagnostic reference } \\
\hline Benign nodules & 816 \\
\hline One category II diagnosis ${ }^{\mathrm{a})}$ & $355(43.5)$ \\
\hline At least two category II diagnoses ${ }^{\mathrm{a})}$ & $410(50.2)$ \\
\hline Surgery & $51(6.3)$ \\
\hline Malignant nodules & 221 \\
\hline Category VI diagnosis ${ }^{a)}$ & $91(41.2)$ \\
\hline Surgery & $130(58.8)$ \\
\hline \multicolumn{2}{|l|}{ Final pathological diagnosis } \\
\hline Benign nodules & 816 \\
\hline Benign follicular nodule ${ }^{a)}$ & $765(93.8)$ \\
\hline Nodular hyperplasia & $29(3.6)$ \\
\hline Follicular adenoma & $20(2.5)$ \\
\hline Thyroiditis & $2(0.2)$ \\
\hline Malignant nodules & 221 \\
\hline PTC & $182(82.4)$ \\
\hline FVPTC & $20(9.0)$ \\
\hline FTC & $14(6.3)$ \\
\hline Other ${ }^{\text {b) }}$ & $5(2.3)$ \\
\hline
\end{tabular}

PTC, papillary thyroid carcinoma; FVPTC, follicular variant papillary thyroid carcinoma; FTC, follicular thyroid carcinoma.

${ }^{a}$ Final diagnosis based on fine-needle aspiration or core-needle biopsy results. ${ }^{b}$ Medullary thyroid carcinoma $(n=3)$, poorly differentiated carcinoma $(n=1)$, lymphoma $(n=1)$. 
Table 2. Distribution of pathologic results according to indications of CNB

\begin{tabular}{|c|c|c|c|c|c|c|}
\hline \multirow[b]{2}{*}{ CNB category } & \multirow{2}{*}{$\begin{array}{l}\text { All nodules } \\
(n=1,216)\end{array}$} & \multirow{2}{*}{$\begin{array}{l}\text { First-line CNB } \\
\qquad(n=856)\end{array}$} & \multicolumn{3}{|c|}{ Second-line CNB with prior FNA results } & \multirow{2}{*}{$\begin{array}{l}\quad \text { P-value } \\
\text { (first-line CNB vs } \\
\text { second-line CNB }\end{array}$} \\
\hline & & & $\begin{array}{l}\text { Prior ND or AUS/FLUS } \\
\text { FNA results }(n=360)\end{array}$ & $\begin{array}{l}\text { Prior ND FNA results } \\
\qquad(n=57)\end{array}$ & $\begin{array}{c}\text { Prior AUS/FLUS FNA } \\
\text { results }(n=303)\end{array}$ & \\
\hline I & $22(1.8)$ & $18(2.1)$ & $4(1.1)$ & $1(1.8)$ & $3(1.0)$ & 0.346 \\
\hline$\|$ & $704(57.9)$ & $529(61.8)$ & $175(48.6)$ & $35(61.4)$ & $140(46.2)$ & $<0.001$ \\
\hline III & $195(16.0)$ & $97(11.3)$ & $98(27.2)$ & $11(19.3)$ & $87(28.7)$ & $<0.001$ \\
\hline IIIA & $58(4.8)$ & $27(3.2)$ & $31(8.6)$ & $2(3.5)$ & $29(9.6)$ & $<0.001$ \\
\hline$\| \mathrm{IIB}$ & $135(11.1)$ & $69(8.1)$ & $66(18.3)$ & $9(15.8)$ & $57(18.8)$ & $<0.001$ \\
\hline IIIC & $2(0.2)$ & $1(0.1)$ & $1(0.3)$ & 0 & $1(0.3)$ & \\
\hline IV & $107(8.8)$ & $56(6.5)$ & $51(14.2)$ & $9(15.8)$ & $42(13.9)$ & $<0.001$ \\
\hline V & $24(2.0)$ & $16(1.9)$ & $8(2.2)$ & $1(1.8)$ & $7(2.3)$ & 0.657 \\
\hline $\mathrm{Vl}$ & $164(13.5)$ & $140(16.4)$ & $24(6.7)$ & 0 & $24(7.9)$ & $<0.001$ \\
\hline
\end{tabular}

Values are presented as number (\%).

CNB, core-needle biopsy; ND, nondiagnostic or unsatisfactory; AUS/FLUS, atypia/follicular lesion of undetermined significance; FNA, fine-needle aspiration.

Table 3. Risk of malignancy in each category of CNB according to the diagnostic criteria for benign nodules

\begin{tabular}{lccc}
\hline \multirow{2}{*}{ CNB category } & \multicolumn{3}{c}{ Criteria for final diagnosis of benignity } \\
\cline { 2 - 3 } I & Criterion I & Criterion II & \multicolumn{1}{c}{ Criterion III } \\
II & $3 / 13(23.1)$ & $3 / 4(75.0)$ & $4 / 24(16.7)$ \\
III & $5 / 701(0.7)$ & $5 / 410(1.2)$ & $14 / 30(46.7)$ \\
IIIA & $14 / 106(13.2)$ & $14 / 51(27.5)$ & N/A \\
IIIB & $7 / 36(19.4)$ & $7 / 21(33.4)$ & N/A \\
IIIC & $6 / 69(10.1)$ & $7 / 29(24.1)$ & N/A \\
IV & $0 / 1(0)$ & $0 / 1(0)$ & $21 / 37(56.8)$ \\
V & $21 / 39(53.8)$ & $21 / 39(53.8)$ & $12 / 12(100)$ \\
VI & $14 / 14(100)$ & $14 / 14(100)$ & $77 / 77(100)$ \\
Total & $164 / 164(100)$ & $164 / 164(100)$ & 183
\end{tabular}

Values are presented as number (\%).

The final diagnosis of malignancy was based on histopathologic readings from surgical resections or FNA and/or CNB diagnosis of malignancy (category VI). Final diagnosis of a benign nodule was made when 1 of the following conditions was fulfilled: criterion I, surgical diagnosis or at least one benign diagnosis on CNB or FNA (category II) where the lesion was not classified as category IV, V, or VI on previous or repeat FNA or CNB, if performed; criterion II, surgical diagnosis or at least two benign diagnoses on FNA and/or CNB or surgical diagnosis only (criterion III).

CNB, core-needle biopsy; FNA, fine-needle aspiration; N/A, not applicable.

The risk of malignancy in each category is presented in Table 3. According to the criteria for a benign diagnosis, the ranges of the malignancy rates for each category (from category I to $\mathrm{VI}$ ) were $23.1 \%-75.0 \%, 0.7 \%-16.7 \%, 13.2 \%-46.7 \%, 53.8 \%-56.8 \%$, $100 \%$, and $100 \%$.

\section{Discussion}

In this report, we present the distribution of thyroid nodules $1 \mathrm{~cm}$ or larger among the categories of the 6-tiered pathology reporting system for CNB along with the malignancy risks in each category according to different diagnostic criteria for benignity. Conventional PTC was the most common malignancy among category VI lesions, while FVPTC and FTC were the most common malignancies among category IV lesions. First-line CNB was associated with a higher rate of conclusive results and a lower rate of inconclusive results than second-line CNB with prior nondiagnostic or AUS/FLUS FNA results. Category IV had an approximately $50 \%$ risk of malignancy, and both categories V and VI had a 100\% risk of malignancy.

When the results of CNB were compared with the results of FNA from previous studies (Table 4), despite inevitable differences in the inclusion criteria, both first- and second-line CNB appeared 
Table 4. Pathologic category distribution of first-line and second-line CNB compared to FNA in previous studies

\begin{tabular}{|c|c|c|c|c|c|c|c|}
\hline \multirow{3}{*}{ CNB category } & \multicolumn{3}{|c|}{ First-line } & \multicolumn{4}{|c|}{ Second-line $e^{a)}$} \\
\hline & \multirow{2}{*}{$\begin{array}{c}\text { CNB } \\
\begin{array}{c}\text { Present study } \\
(n=856)\end{array}\end{array}$} & \multicolumn{2}{|r|}{ FNA } & \multirow{2}{*}{$\begin{array}{c}\text { CNB } \\
\begin{array}{c}\text { Present study } \\
(n=303)\end{array}\end{array}$} & \multicolumn{3}{|c|}{ FNA } \\
\hline & & $\begin{array}{l}\text { Sarkis et al. [25] } \\
\quad(n=2,076)\end{array}$ & $\begin{array}{c}\text { VanderLaan et al. [26] } \\
(n=4,691)\end{array}$ & & $\begin{array}{l}\text { Choi et al. [27] } \\
\quad(n=295)\end{array}$ & $\begin{array}{l}\text { Na et al. [23] } \\
(n=158)\end{array}$ & $\begin{array}{l}\text { VanderLaan et al. [26] } \\
\qquad(\mathrm{n}=287)\end{array}$ \\
\hline I & $18(2.1)$ & $266(12.8)$ & $587(12.5)$ & $3(1.0)$ & $62(21.0)$ & $13(8.2)$ & $12(4.2)$ \\
\hline$\|$ & $529(61.8)$ & $1,551(74.7)$ & $2,941(62.7)$ & $140(46.2)$ & $74(25.1)$ & $61(38.6)$ & $139(48.4)$ \\
\hline III & $97(11.3)$ & $97(4.7)$ & $512(10.9)$ & $87(28.7)$ & $124(42.0)$ & $70(44.3)$ & $80(27.9)$ \\
\hline IV & $56(6.5)$ & $98(4.7)$ & $198(4.2)$ & $42(13.9)$ & $2(0.7)$ & $6(3.8)$ & $25(8.7)$ \\
\hline V & $16(1.9)$ & $16(0.8)$ & $209(4.5)$ & $7(2.3)$ & $8(2.7)$ & $4(2.5)$ & $26(9.1)$ \\
\hline $\mathrm{Vl}$ & $140(16.4)$ & $48(2.3)$ & $244(5.2)$ & $24(7.9)$ & $25(8.5)$ & $4(2.5)$ & $5(1.7)$ \\
\hline
\end{tabular}

Values are presented as number (\%).

CNB, core-needle biopsy; FNA, fine-needle aspiration.

${ }^{a}$ Nodules with atypia (or follicular lesion) of undetermined significance/indeterminate results on previous FNA.

to produce a lower rate of category I results and a higher rate of category $\mathrm{VI}$ results than FNA. This observation reaffirmed that first-line CNB, as well as CNB as a repeat diagnostic tool, may significantly reduce the need for additional repeat FNA/CNB and diagnostic surgery compared to first-line FNA [23,25-27].

If the risk of malignancy had been calculated only on the basis of surgical diagnoses, many benign cases in which surgery could have been avoided would have been excluded from the analysis. Similarly, if the malignancy risk had been based on the FNA/CNB results, some malignant cases would have been incorrectly diagnosed as benign nodules. To compromise between these patterns of overestimation and underestimation of malignancy risk, we calculated the malignancy rates based on three different diagnostic criteria for benignity. Across this wide spectrum of standard references for benign diagnoses, the malignancy rates of categories $I V, V$, and VI were consistent, but the malignancy rates of categories I, II, and III were not.

Suh et al. [20] reported a $9.1 \%$ malignancy rate for category I, while our study indicated a $23.1 \%-75 \%$ malignancy rate for the same category. According to these results, although the proportion of category I results in CNB is low, such results should not be neglected when they occur because of the higher malignancy potential of these cases compared to those with previous nondiagnostic FNA results [18]. The studies by Suh et al. [20] and Choe et al. [21] reported a $2.4 \%-2.5 \%$ malignancy rate in category II, for which our study similarly presented a $0.7 \%-16.7 \%$ malignancy rate. This also suggests that even a category II diagnosis after CNB cannot exclude the possibility of a final diagnosis of malignancy. Additionally, in accordance with the similar results of Suh et al. [20] and Choe et al. [21], nodules with a category IV diagnosis had an approximately $50 \%$ malignancy rate (most commonly FVPTC or FTC), while category $\mathrm{V}$ and $\mathrm{VI}$ diagnoses (most commonly conventional PTC) had nearly $100 \%$ malignancy rates. Because these malignancy rates are greater than those that have been reported for FNA, we may postulate that CNB can reduce the rate of unnecessary surgery compared to FNA [18].

This study has several limitations in addition to its intrinsic limitation as a retrospective study subject to selection bias. First, pathology reporting based on the Korean CNB reporting system has not yet been internationally standardized and widely used in practice. Further global validation of this system from a pathology perspective is needed to reach a consensus regarding the pathologic criteria for each category. Second, the risk of malignancy stratification in this cohort was limited by the diverse spectrum of criteria for benign diagnoses. Although we believe that criterion I may be the most appropriate criterion for calculating the malignancy rate in a clinical context, a worldwide consensus on optimal diagnostic criteria for benignity in a follow-up cohort is needed.

In conclusion, we presented the distribution of nodules among six categories of CNB and the malignancy risks of those categories in a clinical cohort. First-line CNB was associated with a higher rate of conclusive results than CNB of nodules with prior inconclusive FNA results.

ORCID: Hye Min Son: https://orcid.org/0000-0003-1748-0701; Ji-hoon Kim: https:// orcid.org/0000-0002-6349-6950; Soo Chin Kim: https://orcid.org/0000-0002-05111696; Roh-Eul Yoo: https://orcid.org/0000-0002-5625-5921; Jeong Mo Bae: https:// orcid.org/0000-0003-0462-3072; Hyobin Seo: https://orcid.org/0000-0002-97591876; Dong Gyu Na: https://orcid.org/0000-0001-6422-1652

\section{Author Contributions}

Conceptualization: Na DG, Kim JH, Kim SC. Data acquisition: Na DG, Kim JH, Seo H, Bae JM. Data analysis or interpretation: Na DG, Kim 
JH, Kim SC, Yoo RE, Bae JM, Son HM. Drafting of the manuscript: Son HM, Kim JH, Na DG. Critical revision of the manuscript: Son HM, $\mathrm{Kim} \mathrm{JH}, \mathrm{Na}$ DG. Approval of the final version of the manuscript: all authors.

\section{Conflict of Interest}

No potential conflict of interest relevant to this article was reported.

\section{Acknowledgments}

This study was supported by a grant (no. 05-2015-0050) from the SNUH Research Fund.

\section{References}

1. Bongiovanni M, Spitale A, Faquin WC, Mazzucchelli L, Baloch ZW. The Bethesda System for Reporting Thyroid Cytopathology: a metaanalysis. Acta Cytol 2012;56:333-339.

2. Bongiovanni M, Krane JF, Cibas ES, Faquin WC. The atypical thyroid fine-needle aspiration: past, present, and future. Cancer Cytopathol 2012;120:73-86.

3. Orija IB, Pineyro M, Biscotti C, Reddy SS, Hamrahian AH. Value of repeating a nondiagnostic thyroid fine-needle aspiration biopsy. Endocr Pract 2007;13:735-742.

4. Nayar $R$, Ivanovic $M$. The indeterminate thyroid fine-needle aspiration: experience from an academic center using terminology similar to that proposed in the 2007 National Cancer Institute Thyroid Fine Needle Aspiration State of the Science Conference. Cancer 2009;117:195-202.

5. Deveci MS, Deveci G, LiVolsi VA, Baloch ZW. Fine-needle aspiration of follicular lesions of the thyroid: diagnosis and follow-up. Cytojournal 2006;3:9.

6. Alexander EK, Kennedy GC, Baloch ZW, Cibas ES, Chudova D, Diggans J, et al. Preoperative diagnosis of benign thyroid nodules with indeterminate cytology. N Engl J Med 2012;367:705-715.

7. Ryoo I, Kwon H, Kim SC, Jung SC, Yeom JA, Shin HS, et al. Metabolomic analysis of percutaneous fine-needle aspiration specimens of thyroid nodules: potential application for the preoperative diagnosis of thyroid cancer. Sci Rep 2016;6:30075.

8. Renshaw AA, Pinnar N. Comparison of thyroid fine-needle aspiration and core needle biopsy. Am J Clin Pathol 2007;128:370374.

9. Baek JH. Current status of core needle biopsy of the thyroid. Ultrasonography 2017;36:83-85.

10. Na DG, Kim JH, Sung JY, Baek JH, Jung KC, Lee H, et al. Coreneedle biopsy is more useful than repeat fine-needle aspiration in thyroid nodules read as nondiagnostic or atypia of undetermined significance by the Bethesda system for reporting thyroid cytopathology. Thyroid 2012;22:468-475.
11. Samir AE, Vij A, Seale MK, Desai G, Halpern E, Faquin WC, et al. Ultrasound-guided percutaneous thyroid nodule core biopsy: clinical utility in patients with prior nondiagnostic fine-needle aspirate. Thyroid 2012;22:461-467.

12. Trimboli P, Giovanella L. Reliability of core needle biopsy as a second-line procedure in thyroid nodules with an indeterminate fine-needle aspiration report: a systematic review and metaanalysis. Ultrasonography 2018;37:121-128.

13. Hahn SY, Shin JH, Oh YL, Park KW. Ultrasound-guided core needle biopsy techniques for intermediate or low suspicion thyroid nodules: which method is effective for diagnosis? Korean J Radiol 2019;20:1454-1461.

14. Gharib H, Papini E, Garber JR, Duick DS, Harrell RM, Hegedus L, et al. American Association of Clinical Endocrinologists, American College of Endocrinology, and Associazione Medici Endocrinologi Medical Guidelines for Practice for the Diagnosis and Management of Thyroid Nodules: 2016 update. Endocr Pract 2016;22:622-639.

15. Na DG, Baek JH, Jung SL, Kim JH, Sung JY, Kim KS, et al. Core needle biopsy of the thyroid: 2016 Consensus Statement and Recommendations from Korean Society of Thyroid Radiology. Korean J Radiol 2017;18:217-237.

16. Perros P, Boelaert K, Colley S, Evans C, Evans RM, Gerrard G, et al. Guidelines for the management of thyroid cancer. Clin Endocrinol (Oxf) 2014;81 Suppl 1:1-122.

17. Shin JH, Baek JH, Chung J, Ha EJ, Kim JH, Lee YH, et al. Ultrasonography diagnosis and imaging-based management of thyroid nodules: revised Korean Society of Thyroid Radiology Consensus Statement and Recommendations. Korean J Radiol 2016;17:370-395.

18. Cibas ES, Ali SZ. The 2017 Bethesda System for Reporting Thyroid Cytopathology. Thyroid 2017;27:1341-1346.

19. Jung CK, Min HS, Park HJ, Song DE, Kim JH, Park SY, et al. Pathology reporting of thyroid core needle biopsy: a proposal of the Korean Endocrine Pathology Thyroid Core Needle Biopsy Study Group. J Pathol Transl Med 2015;49:288-299.

20. Suh CH, Baek JH, Choi YJ, Kim TY, Sung TY, Song DE, et al. Efficacy and safety of core-needle biopsy in initially detected thyroid nodules via propensity score analysis. Sci Rep 2017;7:8242.

21. Choe JY, Kwak Y, Kim M, Chung YR, Kim HJ, Kim YK, et al. Utility of a formatted pathologic reporting system in thyroid core needle biopsy: a validation study of 1998 consecutive cases. Clin Endocrinol (Oxf) 2018;88:96-104.

22. Haugen BR, Alexander EK, Bible KC, Doherty GM, Mandel SJ, Nikiforov YE, et al. 2015 American Thyroid Association management guidelines for adult patients with thyroid nodules and differentiated thyroid cancer: the American Thyroid Association Guidelines Task Force on Thyroid Nodules and Differentiated Thyroid Cancer. Thyroid 2016;26:1-133.

23. Na DG, Min HS, Lee $H$, Won JK, Seo HB, Kim JH. Role of core 
needle biopsy in the management of atypia/follicular lesion of undetermined significance thyroid nodules: comparison with repeat fine-needle aspiration in subcategory nodules. Eur Thyroid J 2015;4:189-196.

24. Hong MJ, Na DG, Kim SJ, Kim DS. Role of core needle biopsy as a first-line diagnostic tool for thyroid nodules: a retrospective cohort study. Ultrasonography 2018;37:244-253.

25. Sarkis LM, Norlen O, Aniss A, Watson N, Delbridge LW, Sidhu SB, et al. The Australian experience with the Bethesda classification system for thyroid fine needle aspiration biopsies. Pathology
2014;46:592-595.

26. VanderLaan PA, Marqusee E, Krane JF. Clinical outcome for atypia of undetermined significance in thyroid fine-needle aspirations: should repeated fna be the preferred initial approach? Am J Clin Pathol 2011;135:770-775.

27. Choi YJ, Baek JH, Suh CH, Shim WH, Jeong B, Kim JK, et al. Coreneedle biopsy versus repeat fine-needle aspiration for thyroid nodules initially read as atypia/follicular lesion of undetermined significance. Head Neck 2017;39:361-369. 